\title{
El estrecho, dos orillas y dos modelos de gestión mediatizados por un mismo sector: El Turístico
}

\author{
Dra. Ana $M^{a}$ MACÍAS BEDOYA*
}

\section{RESUMEN}

En los últimos años se han producido ciertos cambios en la realidad social y económica marroquí, especialmente en la zona norte del país. Cada vez hay más publicidad de promotoras, muchas de ellas españolas, que ofrecen al mercado nacional y extranjero sus promociones residenciales turísticas, sobre todo en la costa norte marroquí. A la vez, están empezando a producirse algunas demandas de una gestión costera adecuada, ambientalmente correcta, sostenible.

Nos encontramos en un buen momento para evaluar con sentido crítico la evolución del modelo de desarrollo de la costa española, más espontáneo que planificado, y más desarrollista que ambiental. También es un momento oportuno para reflexionar sobre la gestión de nuestro litoral, que parece comienza a reorientarse, mediante la sostenibilidad y también a causa de la crisis inmobiliaria. Cabe esperar que este proceso dé sus frutos más allá de nuestras fronteras, sobre todo en esa otra orilla, la de Marruecos, donde nos miramos continuamente.

\footnotetext{
* Profesora Titular de A.G.R. Universidad de Cádiz.
} 


\section{ABSTRACT}

There have been certain changes to the Moroccan social and economic reality in recent years, especially in the North of the country. There is an increasing amount of publicity by development companies, many of which are Spanish, promoting residential tourist dwellings to both national and international audiences, especially on the Northern Moroccan coast. At the same time, a better coastal management which is both environmentally friendly and sustainable is beginning to be demanded.

This is a good time to critically analyse the progress of the development model for the Spanish coast, which is more spontaneous than planned, and more developmentalist than environmental. It is also a good time to reflect on the management of our coast, which seems heading in a new direction, influenced by the idea of sustainability and the current real estate crisis. It can be hoped that this process will extend beyond our borders, especially on the coast of Morocco, which we continually use as a reference point.

\section{INTRODUCCIÓN: SITUACIÓN, EXPERIENCIAS Y ENFOQUE METODOLÓGICO.}

Hay que admitir que desde el año 2002 en que nuestro grupo de investigación tuvo su primer contacto con la realidad marroquí', si bien indirecto y mirando desde fuera, hasta la fecha actual, las oportunidades de trabajar con y en Marruecos han aumentado considerablemente, tanto en Andalucía como en el resto de España. De hecho, en estos seis últimos años nuestro grupo ha desarrollado un total de cinco proyectos de investigación y formación; siempre dentro de nuestra principal línea de trabajo, la gestión costera.

Parece que estamos en un momento estratégico: Por un lado, Europa muestra un interés indudable por estrechar lazos con dicho país; el caso español es

\footnotetext{
${ }^{1}$ Proyecto titulado Andalucía, frontera de Europa, Acción Coordinada del Plan Andaluz de Investigación financiada por la Consejería de Educación y Ciencia de la Junta de Andalucía (2002-2005) y liderado por el Dr. G. Cano García.
} 
especialmente llamativo ya que, a pesar de su vecindad -o precisamente por ella-, el déficit en las relaciones ha sido una constante en su historia.

Por otro, durante los últimos cinco o seis años se han producido ciertos cambios en la realidad social y económica marroquí, especialmente en la zona norte del país. Al menos así lo hemos percibido los que lo hemos visitado con cierta frecuencia en ese período. Están empezando a surgir indicadores que muestran con claridad el proceso; y una buena parte de ellos lo hacen en el litoral, cuyo constante dinamismo lo hace especialmente sensible a los cambios: Cada vez hay más publicidad de promotoras, muchas de ellas españolas, que ofrecen al mercado nacional y extranjero sus promociones residenciales turísticas, sobre todo en la costa norte marroquí.

A la vez, aunque de forma mucho más sutil y lenta, están empezando a producirse algunas demandas de una gestión costera adecuada, ambientalmente correcta, sostenible... Naturalmente este proceso se limita aún a los ambientes científicos. Sin embargo, en este aspecto hay que tener en cuenta que el Marruecos actual es muy diferente de la España de los años cincuenta, aunque en apariencia sean tan semejantes que solemos olvidamos. La principal diferencia, por su gran trascendencia, radica en el mayor acceso a los medios de comunicación de masas. Este elemento suele conferir mayor dinamismo a los cambios sociales, aunque quizás no estemos aún capacitados para entender hasta qué punto: De forma cotidiana los marroquíes reciben información del modelo social, económico y cultural español... y también del europeo y del mundial. No siempre es una información veraz, completa, que responda fielmente a la realidad... pero casi siempre lo parece, por su abundancia y persistencia.

Este puede ser un buen momento, pues, para evaluar con sentido crítico la evolución del modelo de desarrollo de la costa española, con frecuencia más espontáneo que planificado, más desarrollista que ambiental. En definitiva, parece un buen momento para reflexionar sobre la gestión de nuestro litoral, que parece estar empezando a reorientarse, de la mano suave de la sostenibilidad... pero también de la más férrea de la crisis inmobiliaria. Y esperar que este proceso sirva más allá de nuestras fronteras, sobre todo en esa otra orilla donde nos miramos continuamente. 


\subsection{Límites metodológicos y físicos.}

La perspectiva de este artículo no puede ser otra que la sistémica, tanto por la formación geográfica de la autora, que le hace interpretar el territorio como un cuenco donde, al final, todo converge; como por la línea de investigación en que casi siempre se ha desarrollado su labor investigadora: la gestión integrada. En definitiva, en el litoral, cómo en cualquier otro territorio, los medios físico-natural y socio-económico, incluido el jurídico, funcionan en constante interacción (Barragán, 2003). Durante mucho tiempo lo más fácil para nuestras limitadas capacidades, desbordadas por la magnitud de la realidad, ha sido dividirla. Más adelante, la enorme cantidad de información proporcionada por los sofisticados instrumentos de análisis nos deslumbró y nos hizo olvidar esa realidad primera. Pero cada vez resulta más ineludible la necesidad de volver a mirar al conjunto, de comprenderlo e intentar predecir su evolución. En eso andamos.

En cuanto al marco espacial y territorial, el mismo título del artículo lo describe: las dos orillas del Estrecho. Es cierto que gran parte de este texto está basado en los resultados de dos proyectos de investigación ${ }^{2}$ desarrollados en un tramo muy pequeño del litoral mediterráneo: los 20 primeros kilómetros que hay entre Ceuta y Cabo Negro (entre las poblaciones marroquíes de Fnideq y M'diq). Pero ello no impide que sean generalizables; En primer lugar, porque dicho ámbito no fue elegido al azar, sino como zona-piloto que consideramos representativa de lo que está sucediendo en toda la costa mediterránea; En segundo lugar, porque a lo largo de esa labor investigadora se tuvo siempre una perspectiva amplia, con la certeza de que a medio y largo plazo intentaríamos trabajar otras zonas del litoral marroquí. Por otra parte, dado el carácter centralizado del sistema, los aspectos jurídicos son extensibles, con escasos matices, a toda la costa de Marruecos. El caso de los económicos es semejante, variando más la cantidad que la cualidad de los procesos... en realidad parece como si todo el litoral marroquí, con su gran diversidad natural, estuviera pendiente de una gran transformación, cuyas primeras, pero más rotundas, manifestaciones están teniendo lugar en su parte mediterránea.

\footnotetext{
${ }^{2}$ El A37/02: Estudios técnicos para la gestión integrada de los desarrollos turísticos en el tramo costero CeutaCabo Negro (NE-Marruecos); y su continuación: el AM3/04: Propuesta de acciones para desarrollar el modelo de gestión integrada en la costa marroquí entre Ceuta y Cabo Negro, ambos financiados por la Dirección General de Asuntos Europeos y Cooperación Exterior (Consejería de Presidencia, Junta de Andalucía).
} 
Las alusiones a la otra orilla, la española, se han limitado a lo estrictamente necesario, esperando que la experiencia y lógica de los lectores les permitan elaborar sus propias conclusiones, por lo demás, más que evidentes.

\section{LAS DOS ORILLAS. DESDE EL PUNTO DE VISTA FÍSICO- NATURAL: UN ENTORNO FAVORABLE PARA EL TURISMO.}

"El estrecho de Gibraltar es un angosto paso, de solo, 14 Km. cuya posición le proporciona características originales, tanto desde el punto de vista climático como oceanográfico y biológico: encrucijada entre el sur de Europa y el norte de África, lugar de encuentro brusco entre las aguas procedentes del Mediterráneo y Atlántico. Si a ello añadimos lo estratégico de su situación, tanto para las rutas migratorias de las aves, como de los peces y mamíferos marinos... debemos reconocer que estamos ante un ecotono, un lugar donde comunidades animales y vegetales procedentes de ecosistemas distintos se mezclan, donde abundan los endemismos, donde la biodiversidad se muestra extremadamente generosa" (Bello, et al. 2005).

Pero avancemos un poco más, salgamos del Estrecho estricto, vayamos a las dos orillas mediterráneas, española y marroquí, entre las que se sitúa; y pensemos, sobre todo, en el litoral como recurso turístico, que es el motivo del presente artículo.

Las condiciones climáticas son, en general, las típicas del clima mediterráneo: precipitaciones más bien escasas y muy concentradas en una serie de meses al año, altos niveles de insolación y ausencia casi completa de invierno térmico; ello garantiza las posibilidades de baño prácticamente todo el año.

Respecto a las características de las playas, el ámbito mediterráneo tiene un rango micro-mareal (de 0,8-1 m. en mareas vivas), lo cual se manifiesta en estrechas playas secas, que dejan escasa superficie de actuación al viento, con lo que su capacidad para generar dunas es limitada. Por otra parte, debido a los diversos accidentes rocosos, este litoral suele compartimentarse en células de funcionamiento independiente ${ }^{3}$. Hablando siempre en general, se trata de ámbitos relativamente

\footnotetext{
${ }^{3}$ Los fenómenos de erosión, tanto como los de transporte y sedimentación tienen lugar sólo dentro de un radio de acción cercano.
} 
estables, pero lo reducido de los cordones dunares limita sus posibilidades de recuperación frente a un posible incremento de los procesos erosivos; por otro lado, su capacidad de acogida es pequeña como consecuencia de las dimensiones de las playas secas (Anfuso, et al, 2006).

En definitiva, tanto las características del clima cómo las de las playas conforman un recurso muy valioso para el sector turístico en su modelo de "sol y playa"; Un recurso abundante y bien definido, aunque no exento de fragilidad.

\section{LAS DOS ORILLAS: DESDE EL PUNTO DE VISTA SOCIO- ECONÓMICO.}

Hace ya algunas décadas que Marruecos se ha unido al proceso de litoralización que desde los años cincuenta se viene produciendo en el mundo. Así, se ha pasado de los 9,4 millones de habitantes en 1982 a los 14,8 en 2000 (ONEM, 2001). Este incremento es más evidente en el caso de la población urbana, ya que entre 1982 y 1994 se registró una tasa media de crecimiento anual del $4,1 \%$ en las ciudades litorales, con respecto al $2,6 \%$ del total urbano nacional. Además, durante la última década (1991-2001) el litoral mediterráneo ${ }^{4}$, en particular, ha conocido un crecimiento anual algo más intenso $(2,3 \%)$ que el conjunto del litoral marroquí $(2,1 \%)$ y, aunque sólo tuviésemos intuición... es obvio que el sector turístico y la cercanía de Europa tienen algo que ver.

Es bien sabido que la litoralización constituye un fenómeno complejo; Con el tiempo la concentración demográfica en el litoral se va acelerando y retroalimentando progresivamente: más personas atraen a más actividades y más actividades a más y más personas. Una de las manifestaciones del mismo, quizás la más evidente, es el crecimiento continuo de la demanda residencial, que supone un incremento paralelo de la presión sobre el suelo ${ }^{5}$. Estrechamente relacionado con todo ello está

\footnotetext{
${ }^{4}$ Datos provinciales de Tetuán.

${ }^{5}$ No hay que olvidar que el problema es en realidad mucho más complejo, pues supone la aparición de grandes desequilibrios territoriales, especialmente graves cuando afectan a países subdesarrollados, cuya capacidad para contrarrestar o frenar el proceso es limitada.
} 
el sector turístico, a la vez causa y consecuencia, solución y problema: Atrae mano de obra cuyas necesidades residenciales hay que cubrir y, sobre todo, un considerable número de habitantes estacionales ${ }^{6}$ cuyas residencias son, también a la vez, reclamo y respuesta, oferta y demanda. De todo ello nos ocuparemos en este artículo.

Según nuestros datos, nuestra zona de estudio ha venido orientando su economía hacia dicho sector desde hace casi dos décadas aunque, especialmente, en los últimos cinco años. De hecho, buena parte de las demás actividades identificadas estaban vinculadas con el mismo (construcción, extracción, tráfico de pasajeros y mercancías, producción artesanal...). En la actualidad se estima que cada empleo turístico directo generado en el norte de Marruecos induce otro indirecto en los sectores "de acompañamiento" (Bello, et al. 2006). En el caso de la provincia de Tetuán ello afecta aproximadamente a un $20 \%$ de la población activa ${ }^{7}$. Los proyectos turísticos en marcha supondrán, según prevén las autoridades locales, la práctica desaparición del desempleo en la zona ${ }^{8 ;}$ y eso sin tener en cuenta que los datos oficiales no incluyen el empleo irregular. En consecuencia, podemos afirmar que el sistema muestra una tendencia clara hacia el monocultivo del sector turístico, con todas sus consecuencias.

El otro gran sector de actividad es el primario (agricultura, ganadería y pesca) que sigue ocupando a gran parte de la población activa (el 22,5\%), sobre todo del entorno rural inmediato a la zona de estudio. Sus cambios han sido escasos, lo cual no quiere decir que evolucione al margen del turismo; En la actualidad, y debido en parte a la estacionalidad de dicha actividad, constituye para muchos habitantes de la zona una fuente de ingresos complementaria.

En definitiva, nos encontramos ante una realidad muy contrastada: Por un lado, actividades agropecuarias de subsistencia... por otro, las recién implantadas

\footnotetext{
${ }^{6}$ Durante dos meses al año (julio y agosto) la población de las ciudades costeras de nuestra zona de estudio se duplica.

${ }^{7}$ Estadísticamente hablando, el 10\% correspondiente a las actividades "de acompañamiento" se asigna a otros sub-sectores, algunos dentro del propio sector terciario (comercial, transporte, etc.), otros dentro del secundario (producción artesanal, fabricación de materiales de construcción, construcción, etc.).

${ }^{8}$ En Bello et al. (2006) se indica que con los proyectos turísticos que se estaban realizando en el 2004-2005 se preveía la creación de más de 15.000 puestos de trabajo. En la actualidad hay varios proyectos nuevos en desarrollo.
} 
actividades turísticas, extraordinariamente dinámicas y con gran capacidad para reorientar todo el sistema socio-económico de la zona. Hasta hace poco la carretera RN-13: Ceuta-Tetuán, paralela a la costa, servía de línea divisoria entre ambos mundos (ver figura 1): los usos turísticos se implantaban desde ella hacia el mar y los de cultivo hacia el interior. Sin embargo, en los últimos años se ha iniciado la ocupación de la parte superior por complejos turísticos, invadiendo el espacio de los usos agrícolas tradicionales. Es evidente qué actividad está ganando la batalla por el territorio; en realidad, habría que admitir que ya la ha ganado pues, a día de hoy, en primera línea de playa quedan muy pocos metros cuadrado por urbanizar entre Ceuta y Cabo Negro.

Pero, entremos un poco más en el tipo de oferta turística de la costa mediterránea marroquí. Cómo puede comprobarse en la figura 1: el modelo constructivo es longitudinal, paralelo a la costa, con escasa penetración hacia el interior y basado en la primera línea de playa; o en la primerísima línea de playa, como confirmó el trabajo de campo. Un modelo en el que predominan las unidades aisladas de los núcleos de población preexistentes, M'diq y Fnideq.

La evolución del sector en la zona también es significativa: Tras su declaración en 1965 como "Zona de Ordenación Prioritaria" para el turismo, hasta 1972 se fueron construyendo los primeros establecimientos: hoteles de alta categoría. Después el crecimiento fuelento, respondiendo exactamenteal estado de lademanda. Desdefinales de los 80 , sin embargo, el proceso empezó a acelerarse y la oferta se reorientó hacia la segunda residencia, cuyo desarrollo ha sido especialmente intenso en los últimos 15 años. Hay que tener en cuenta que dicha oferta es la que menos empleo genera, una vez superada la etapa constructiva, sobre todo en comparación con los hoteles. Además, cuando se centra en la construcción horizontal, cómo es el caso, también es la que más territorio consume.

La oferta actual de nuestra zona-piloto está orientada hacia los grandes complejos turísticos que incluyen, casi siempre, un hotel de alta categoría y muchas residencias secundarias (aparta-hoteles y, sobre todo, chalés). Las más de 9000 plazas previstas en los nuevos proyectos no hacen sino confirmar dicha tendencia. A todo 
ello se añaden, puntualmente, puertos deportivos, vinculados a zonas residenciales de cierta categoría; y campamentos ${ }^{9}$ con escasos servicios e infraestructuras, que se saturan durante el verano.

En conclusión, podemos decir que el modelo turístico de la zona, se ubica plena e íntegramente en la oferta clásica de "sol y playa". La necesidad de abundante insolación y temperaturas adecuadas nos dibujan una actividad estacional, desarrollada exclusivamente en los meses de verano. Es importante recordar que el recurso "playa" es, también, parte insustituible del binomio; por tanto, el mantenimiento de la cantidad y calidad de arena es imprescindible. Sin embargo, los datos que se han dado sobre el modelo constructivo y las características naturales de las playas permiten prever que las relaciones entre ambos serán conflictivas; en realidad ya lo están siendo.

Por otra parte, como ya se dijo, la oferta se ha centrado en el modelo menos rentable a medio plazo: la segunda residencia -y la acampada-, dirigidas fundamentalmente a clientes nacionales de poder adquisitivo medio-bajo. En definitiva, se está apostando por una tipología que obliga a garantizar una oferta competitiva, es decir, barata y, en consecuencia, abundante. Estacionalidad y carácter masivo se manifiestan en problemas diversos: de tráfico, abastecimiento, gestión de residuos, etc. Además, el aislamiento territorial de los complejos turístico implica la obligación de dotarlos de equipamientos e infraestructuras específicos, de los que no se beneficia el conjunto de la sociedad y que, obviamente, sólo son utilizados durante la temporada turística.

En el mismo sentido, se está apostando por un modelo que ya ha demostrado claramente sus limitaciones en la otra orilla: Ciertamente, en este aspecto ambas parecen idénticas, como si se tratara de un juego de espejos... En general, podemos afirmar que es la oferta más extendida, donde hay una mayor y más experimentada competencia... Y cuando el mercado está saturado sólo puede destacarse ofreciendo precios más competitivos.... De una u otra manera, parece que todo acaba conduciendo a la masificación y, en consecuencia, a la sobreexplotación.

\footnotetext{
${ }^{9}$ Camping.
} 
Evolución del litoral marroquí entre Ceuta y Cabo Negro.

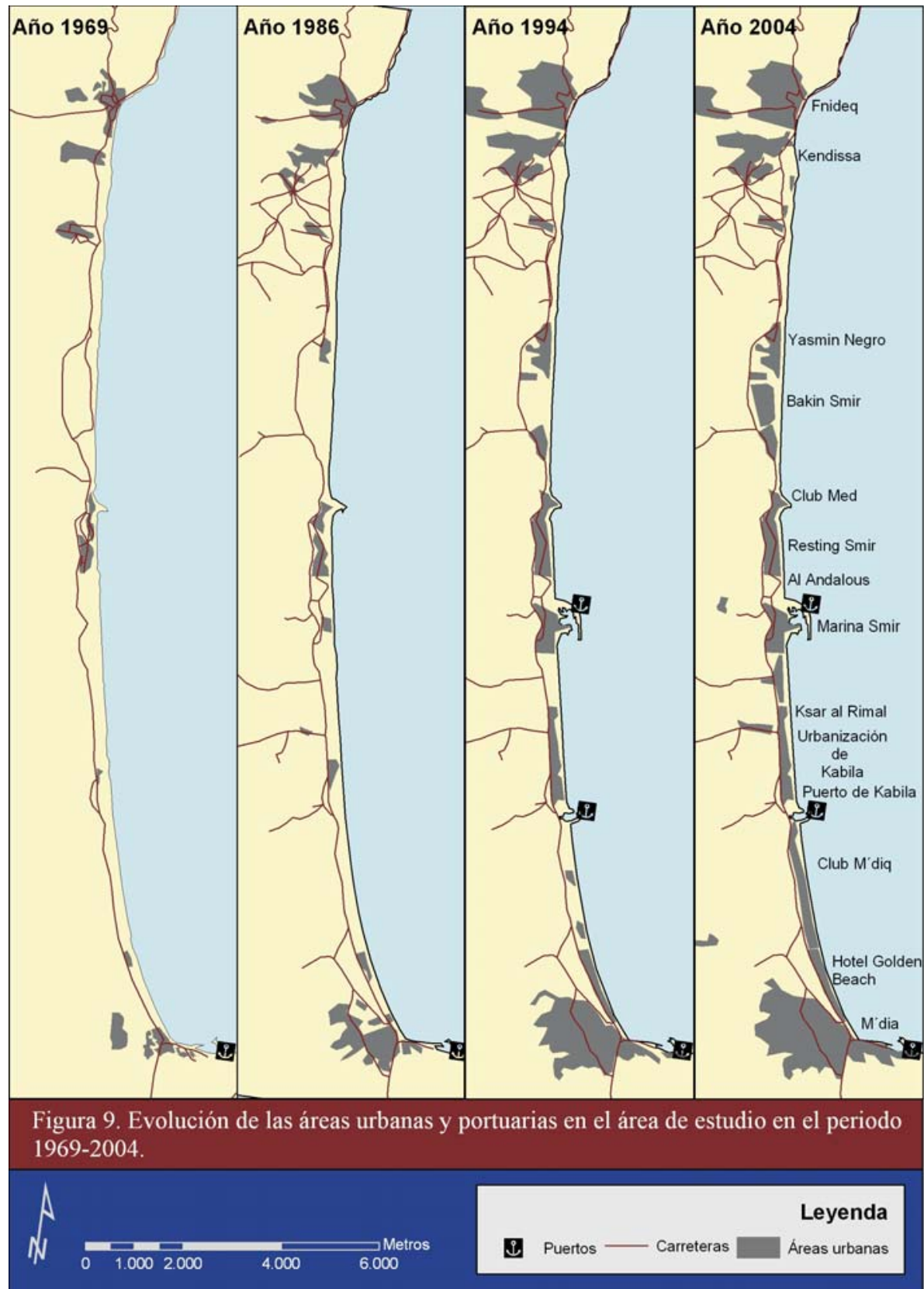

Fuente: Bello, et al. 2006.

Las ilustraciones que aperecen en esta publicación en blanco y negro (para ahorrar costes de impresión) pueden verse en color en:

http://www.institucional.us.es/revistas/revistas/andaluces/htm/indice27.htm 
Finalmente, es preciso aludir, aunque sea de forma superficial, al hecho de que la puesta en el mercado de las segundas residencias se desarrolla en buena parte al margen de la legalidad. Esto supone menos ingresos para la administración pública, en particular la local que, por el contrario, debe proporcionar servicios, abordar retos e intentar resolver gran cantidad y variedad de problemas que el sistema produce 0 padece.

\section{PROBLEMAS, IMPACTOS, CONFLICTOS...}

Con el objeto de analizar de forma ordenada y sistemática la compleja realidad económica y ambiental de nuestra zona-piloto, establecimos el siguiente sistema de trabajo, basado en la metodología propia de la gestión integrada: En primer lugar, identificamos los usos y actividades más frecuentes en la zona, desechando sólo los excepcionales; En segundo, desglosamos las actuaciones que lleva aparejado el desarrollo de cada uno de ellos; En tercer lugar, tratamos de identificar los impactos más relevantes ocasionados por las mismas (en primero, segundo e incluso tercer grado). Aquí no sólo se incluyeron los impactos evidentes, sino también aquellos otros que, según nuestra experiencia, eran predecibles de no cambiar las tendencias detectadas. En cuarto y último lugar, se llevó a cabo un análisis en red ${ }^{10}$ de los impactos, identificando tanto los usos y las actividades implicados en ellos (causas), como los afectados (consecuencias).

Se trataba de superar el límite tradicional de los impactos ambientales, incluyendo los efectos que los mismos, originados por y en el sistema económico, generan sobre el propio sistema económico, provocando "deseconomías" que, con frecuencia, quedan al margen de los diagnósticos, evaluaciones y contabilidades.

\footnotetext{
${ }^{10}$ Fischer, 1999.
} 


\subsection{Consecuencias ambientales del modelo turístico.}

Es evidente que la construcción de edificios e instalaciones orientados a la residencia turística es la principal responsable de la transformación que ha sufrido en las últimas décadas nuestra zona de estudio. Las actuaciones se han desarrollado y continúan haciéndolo, en general, sobre el cordón dunar, a escasa distancia de la orilla, dada la estrechez de estas playas, y con una disposición de las edificaciones paralela a la costa. Cómo ya se dijo, sólo cuando la primera línea se ha agotado, se ha empezado a ocupar también la segunda, más allá de la carretera RN-13: CeutaTetuán.

El efecto más importante de la "ocupación" física de este territorio, aparte de suponer la destrucción completa del ecosistema preexistente, es la alteración de la dinámica costera; Así pues, al destruirse las reservas naturales de arena que constituyen las dunas, se impide la recuperación cíclica de las playas. Las "pantallas" arquitectónicas constituidas por los edificios refuerzan dicho proceso, impidiendo el transporte de los sedimentos por el viento. Para culminarlo, paralelamente al aumento de la construcción ha tenido lugar una intensificación de la extracción de áridos. Todas estas actuaciones hacen estas playas más sensibles a los temporales y, en general, las dejan más expuestas ante los procesos erosivos.

Además de la edificación residencial, otros usos constructivos, las infraestructuras, muestran comportamientos parecidos a los descritos: Ilevan consigo la ocupación exclusiva y excluyente del territorio, constituyen "barreras" físicas y necesitan áridos para su construcción. En consecuencia, generan también efectos semejantes, impidiendo o limitando los ciclos naturales de la dinámica costera.

Las infraestructuras de protección y defensa costera, en particular diques y espigones, inciden de forma aún más directa en la dinámica costera, sobre todo interrumpiendo la deriva litoral y variando los lugares de sedimentación y erosión. Las instalaciones portuarias las incorporan necesariamente, lo que hace que, en general, sean muy impactantes. Sin embargo, los puertos deportivos responden a una lógica económica y territorial que los hace especialmente agresivos: se trata de instalaciones pequeñas, muy dinámicas, que casi siempre son un mero complemento 
de desarrollos inmobiliarios paralelos ${ }^{11}$. En nuestra zona-piloto (con, apenas $20 \mathrm{Km}$. lineales de costa) hay tres instalaciones portuarias (Marina Smir, el puerto de Kabila y el de M'diq), dos de las cuales son puertos deportivos. La tendencia es, como mínimo, preocupante.

En cuanto a los residuos, lógicamente su aumento es proporcional al crecimiento demográfico y urbanístico. En el marco de nuestros proyectos no hemos realizado análisis ni estudios de calidad de las aguas. Sin embargo, según los datos de población manejados y la situación de las infraestructuras de depuración, deben estar manifestándose ya algunos problemas o a punto de hacerlo. De hecho, cada complejo turístico cuenta con su propia red de aguas residuales, pero sólo algunos de ellos con estaciones de depuración, siempre de capacidad limitada y titularidad privada, lo que limita el control de su funcionamiento. Podemos afirmar que, en temporada alta, prácticamente 200.000 habitantes vierten sus residuos, sin tratamiento alguno, directamente al mar.

La situación no es mejor respecto a los residuos sólidos. Los vertederos legales existentes no son más que meros acumuladores, difíciles de controlar: generan olores, se dispersan con el viento y, sin duda, están generando procesos de lixiviado importantes. Además, las limitaciones del servicio de recogida y gestión, junto con la inexistencia de vertederos para residuos específicos, hacen que los depósitos ilegales se diseminen por todo el territorio y que los perímetros de las urbanizaciones se conviertan en verdaderas escombreras, reduciendo considerablemente la calidad del entorno.

\subsection{Consecuencias socio-económicas del modelo turístico}

En general, la presión que ejerce la estructura económica sobre el soporte natural suele acabar afectando, de nuevo, a la estructura económica, y de forma más inmediata de lo que suele pensarse. En la tabla 1 pretendemos mostrar como el compendio de usos, actividades y actuaciones que conlleva el modelo turístico en

\footnotetext{
${ }^{11}$ Los puertos comerciales (y pesqueros) son normalmente el resultado de una evolución larga a lo largo del tiempo y responden a demandas que superan lo meramente local. En palabras de Barragán (1993) "suelen estar bien definidas espacialmente" y "no es frecuente que generen rápidos procesos expansivos". Tradicionalmente los profesionales de la ordenación del territorio, especialmente los que se dedican al litoral, han considerado las instalaciones portuarias sencillas de controlar en general.
} 
nuestra zona impone, a través de su presión sobre el medio, algunas limitaciones al sistema económico.

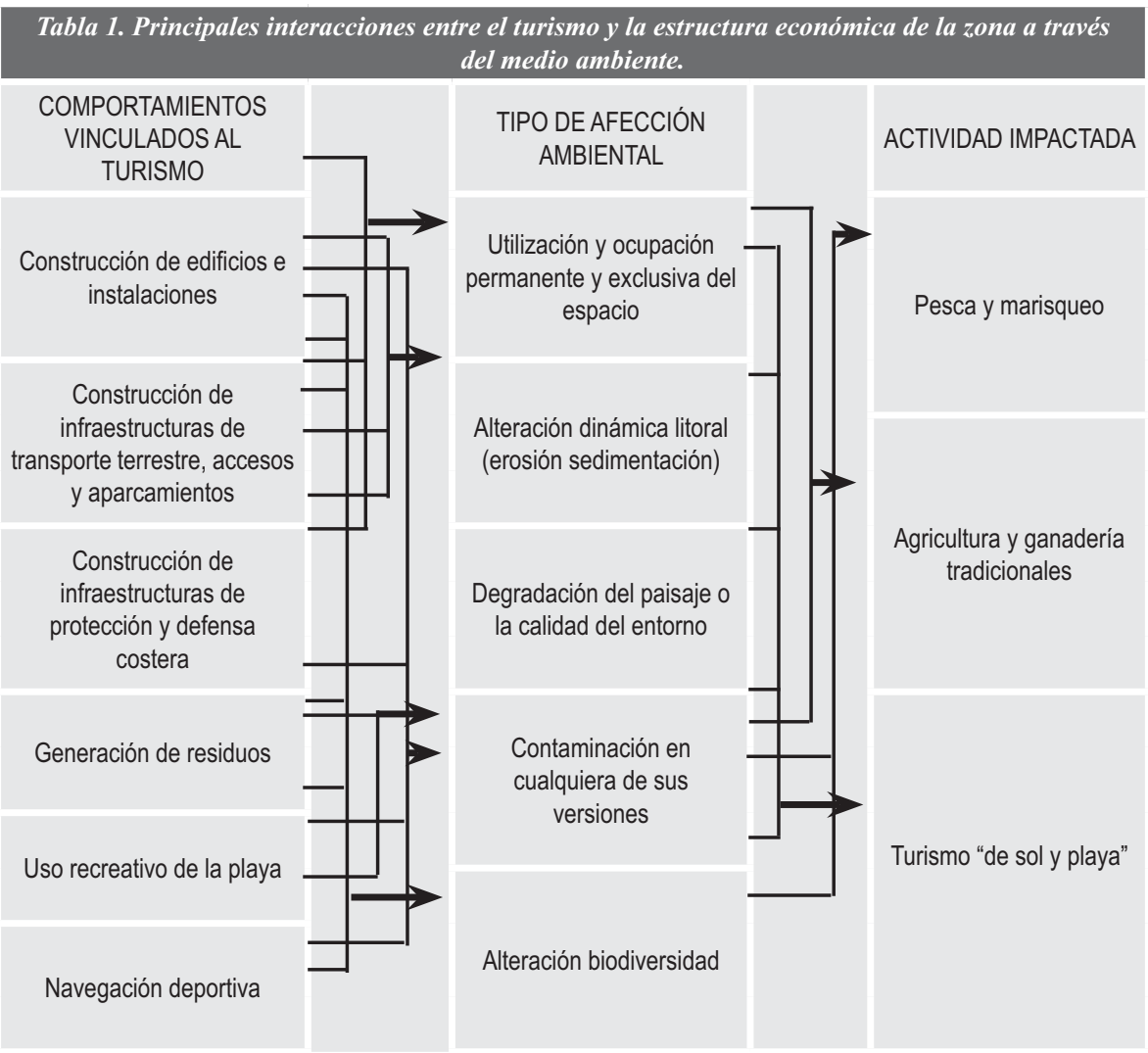

Fuente: Bello et al. 2006

\subsubsection{Limitaciones impuestas al propio sector turístico y de ocio.}

Como hemos dicho, el modelo turístico de nuestra zona de estudio se sitúa en la oferta "de sol y playa". Sin embargo, muchos de los comportamientos propios de su desarrollo afectan profundamente a una parte fundamental de ese binomio, la 
playa $^{12}$; ya sea respecto a su propia existencia, a su anchura, a la cantidad o calidad de su arena y del agua de baño. En el futuro, a corto o medio plazo, serán inevitables inversiones continuas en regeneraciones si se quiere conservar el sistema.

La situación se completa con el deterioro del paisaje y las dificultades para su contemplación: su desnaturalización y vulgarización mediante modelos constructivos alóctonos; la masiva ocupación de la primera línea de playa, que limita o condiciona el crecimiento de la oferta hacia el interior...

Es indudable que todo ello acaba incidiendo también en los precios y reduciendo la rentabilidad del sector. En definitiva, nos estamos refiriendo a un tipo de oferta turística que suele entrar en un circulo vicioso: a más construcción más impactos y degradación; a más degradación menores precios y rentabilidad final; menor rentabilidad que se intenta compensar aumentando la masificación... que genera más construcción y más impacto... y así sucesivamente. El mismo proceso que desde hace años se ha puesto en evidencia en la Costa del Sol andaluza y del que tan difícil resulta salir, sobre todo cuando todo el sistema económico depende, casi por completo, del este sector.

La "autofagia ${ }^{13 "}$ no es un comportamiento exclusivo del sector turístico, es común a casi todas las actividades directamente relacionadas con la explotación de los recursos naturales. Pero, en este caso, la percepción del problema es más difícil; Por un lado, porque una parte de la degradación se produce sobre recursos no mensurables o escasamente definidos, como es el caso de la belleza del paisaje; Por otro, porque la sociedad no conoce ni considera las características y el funcionamiento del recurso del que depende, en este caso las playas. Ignorancia grave en tanto que la tendencia parece ser el monocultivo y, por tanto, es la subsistencia lo que está en juego.

\footnotetext{
${ }^{12}$ En algunas zonas del Levante español se ha puesto en peligro no sólo este elemento, sino todo su conjunto; ya que los propios edificios residenciales proyectan su sombra sobre la arena desde el mediodía.

${ }^{13}$ Por canibalismo.
} 


\subsubsection{La evaluación global del modelo económico.}

Es muy importante plantear si los beneficios derivados de este modelo económico son suficientes como para compensar futuras inversiones de mantenimiento, o como para que el conjunto de cambios merezca la pena y lo vaya a continuar haciendo durante mucho tiempo. En ese sentido, es preciso diferenciar quienes obtienen esos beneficios de aquellos que sufren los efectos... y de los que van a asumir las labores de mantenimiento y los riesgos... porque suele ocurrir que no son los mismos. De igual modo, también es preciso prever consecuencias para el corto, medio y largo plazo.

Desgraciadamente, los datos con la que hemos contado a este respecto son escasos y algunos de ellos exclusivamente cualitativos, pues se han obtenido a través de entrevistas con técnicos y estudiosos de la zona: lo limitado de los recursos de los proyectos (en cuanto a personal, financiación y tiempo), y las dificultades para obtener información en Marruecos ${ }^{14}$ impidieron mejores resultados. Sin embargo, las opiniones de interlocutores cualificados, sobre todo cuando se repiten y son coherentes con otros procesos que sí se han podido comprobar, son significativas; a continuación exponemos las más relevantes y repetidas.

En primer lugar, se está produciendo una sustitución de las actividades tradicionales (de subsistencia) del sector primario por el terciario. Esto es evidente, sobre todo, en los grupos sociales más jóvenes. Paralelamente, se está produciendo cambios de uso en el territorio, desde la agricultura y ganadería hasta el residencial, que afectan a toda la zona, incluidos los municipios rurales del entorno. En realidad, el sistema parece estar tendiendo hacia el monocultivo de un modelo turístico cuyas características ya se han definido; y es dicho sector el que está parece estar "tirando" de todo el sistema hoy día.

En segundo lugar, se está produciendo también un aumento en el número de empresas dedicadas a la fabricación artesanal y los materiales de construcción, así como en el contingente de población empleado en la construcción. Algo parecido pasa con el resto del sector servicios (terciario) vinculado al turismo: restauración y

${ }^{14}$ Información de calidad, fiable, elaborada, periódica, accesible, etc. 
hostelería; jardinería, limpieza, mantenimiento y reparaciones; seguridad, comercio al por menor, etc. ${ }^{15}$

Es cierto que la apreciación de los entrevistados respecto a los cambios en las actividades industriales "no relacionadas con la construcción" y comerciales es confusa; seguramente porque se están produciendo de forma más paulatina. Pero, en general existe la impresión generalizada de que los beneficios del sector turístico serían mayores si no estuviera basado en complejos prácticamente autosuficientes y la temporada fuese algo más amplia. En este sentido, es indudable que una oferta turística algo más diversificada, no exclusivamente centrada en el "sol y playa", sería beneficiosa: ampliaría el ámbito de acción hacia el interior, distribuyendo más y mejor el desarrollo y los impactos; en definitiva, amortiguaría o evitaría el desequilibrio territorial al que se está tendiendo. "Seguramente se estaría dibujando una actividad menos dinámica a corto plazo, pero también menos estacional, más perdurable en el tiempo, más sostenible y con mayor capacidad de beneficiar a los habitantes de la zona" (Bello, et al. 2006).

Por último, es importante tener en cuenta la fragilidad que confiera a cualquier sistema económico el monocultivo de una actividad, especialmente cuando dicha actividad es muy sensible a las coyunturas y dependiente de muchos elementos: de una situación de bonanza económica en los países de origen, que anime a los clientes a gastar una parte de sus recursos en ocio; de una situación de estabilidad social y política en el país receptor, que lo haga atractivo y evite cualquier sensación de inseguridad; de la superación de barreras culturales ${ }^{16}$, etc. Si cualquiera de esos aspectos evoluciona desfavorablemente podemos encontrarnos ante un territorio completamente transforma-do, desprovisto para siempre de sus atractivos originarios e inútil desde el punto de vista económico: Ese es el peor de los impactos, el impacto completo.

\footnotetext{
${ }^{15}$ Poco más puede decirse al respecto, pues resulta difícil analizar los datos de empleo relacionados con este sector, dada la manifiesta marginalidad de algunas de sus expresiones.

${ }^{16}$ Seguramente esas dos últimas cuestiones constituyen algunas de las causas que han provocado el retraso de Marruecos como destino turístico competitivo.
} 


\section{LAS DOS ORILLAS DESDE EL PUNTO DE VISTA JURÍDICO- ADMINISTRATIVO.}

El apartado jurídico-administrativo es fundamental a la hora de completar el estudio de cualquier territorio desde una perspectiva integrada. $Y$ lo es no sólo porque supone un elemento clave del sistema, aquel creado por los seres humanos para ordenar sus relaciones sociales y con el entorno; sino porque está demostrado que, en muchas ocasiones, sus deficiencias son el origen último de problemas cuyos síntomas, en forma de impacto o conflicto, casi siempre sólo interpretamos en clave ambiental y, algunas veces, escasas por lo general, también en clave económica.

Dado que la experiencia de nuestro grupo de investigación se centra sobre todo en la gestión, este apartado se abordó con especial interés, utilizando para ello el modelo de diagnóstico que el Dr. Barragán ha ido desarrollando y perfeccionando tras su aplicación en otros territorios ${ }^{17}$. Se trata de un decálogo que permite dirigirla investigación, facilitando la síntesis y la eficiencia, hacia los aspectos estructurales del sistema jurídico en lo que respecta a la gestión integrada del litoral. Sin embargo, en esta ocasión nos centraremos sólo en los dos aspectos fundamentales: la normativa y la política.

\subsection{La normativa.}

El Dahir de 1926 sobre la Policía del Dominio Público Marítimo-Terrestre (en adelante DPMT) es la única disposición vigente dedicada específicamente a la gestión costera, aunque se restrinja al DPMT, cuestión que sucede con frecuencia en los países herederos del derecho romano ${ }^{18}$. No obstante, la regulación que conlleva es escasísima; básicamente: Se prohíbe la colocación de cualquier objeto o edificación entre sus límites o dificultando la libre circulación por él mismo; así, mismo, la creación de depósitos y la realización de excavaciones o extracciones de materiales.

\footnotetext{
${ }^{17}$ Este modelo aparece de forma explícita en: Barragán, 2003a; Barragán, 2003b y Barragán, 2004. De forma implícita en: Barragán et al., 2003 y Barragán, et. al., 2004. A ello habría que añadir otras publicaciones donde el citado modelo se encontraba aún en fase de elaboración: Barragán, 2001a y Barragán, 2001b.

${ }^{18}$ La principal peculiaridad de los bienes de Dominio Público es que tanto su propiedad como su gestión dependen directamente de las Administraciones Públicas.
} 
Para completar el sistema hay que considerar también el Dahir de 30 de noviembre de 1918, relativo a la ocupación temporal del Dominio Público (en adelante DP), cuyas disposiciones más generales son las que aparecen en la tabla 2. Mucho más recientemente, a través de la Ley 12-03 relativa a los Estudios de Impacto Ambiental. Allí se establece que todas las personas físicas o jurídicas que soliciten autorización o concesión de ocupación del DPMT debe realizar una Evaluación de Impacto Ambiental (en adelante EIA), cuyos contenidos mínimos aparecen en la tabla 3.

\section{Tabla 2. Disposiciones Generales del Dahír de 1918.}

- Los bienes de Dominio Público son inalienables e imprescriptibles y, en ningún caso, pueden ser objeto de una cesión definitiva.

- Pueden ser ocupados de forma temporal por particulares o colectividades territoriales, siempre que el interés público de éstos no se vea afectado. Para lograr la ocupación temporal debe obtenerse:

- $\quad$ Una autorización de la administración pública competente.

- $\quad$ Una concesión; que se otorga a cualquier persona de derecho público o privado para llevar a cabo un servicio público (que puede ser la construcción, el mantenimiento o la explotación de un edificio público).

Fuente: Bello et al., 2006.

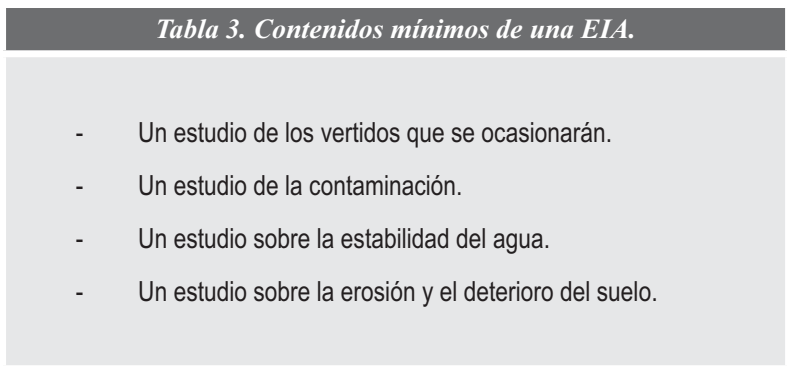

Fuente: Bello et al., 2006.

Sin embargo, aunque el control del uso de dicho espacio no está bien definido, la principal carencia del sistema es la ausencia de una delimitación del mismo. Para encontrar algo a este respecto, hay que buscar en el Dahir de 1 de julio de 1914 
sobre el DP que, en realidad, es poco más que un inventario (ver tabla $\left.n^{\circ} 4\right)$. Ni la enumeración ni el criterio numérico utilizado, "los seis metros más allá de la altura que alcanza el agua", permiten incluir todos los elementos necesarios para garantizar la conservación completa, funcional y autosuficiente de los sistemas costeros (cordones dunares, acantilado, playa seca, etc.). Y, naturalmente, no pueden servir de soporte a una gestión que lo pretenda. De igual modo, también está sin resolver el contacto entre el DPMT y el DP Hidráulico, tan trascendental para la gestión de los estuarios, espacios especialmente complejos, delicados y valiosos.

\begin{tabular}{|c|c|}
\hline RELACIÓN & BIENES INCLUIDOS \\
\hline Posible DPMT & $\begin{array}{l}\text { - La ribera del mar hasta el límite máximo que alcanza el agua; incluyendo } \\
\text { también una zona de } 6 \text { m. medida a partir de dicho límite; } \\
\text { - } \quad \text { Las radas, los puertos, las ensenadas y sus dependencias; } \\
\text { - } \quad \text { Los faros, las señales luminosas, las balizas, y generalmente cualquier obra } \\
\text { destinada a la iluminación y señalización de la costa, y sus dependencias; }\end{array}$ \\
\hline $\begin{array}{l}\text { Entre el DP } \\
\text { Hidráulico }{ }^{19} y \\
\text { el DPMT }\end{array}$ & $\begin{array}{l}\text { - Todas las masas de agua, superficiales o subterráneas, los ríos y las fuentes de } \\
\text { cualquier tipo; } \\
\text { - Los lagos, los estanques y sebkhas, así como las lagunas, las marismas y los } \\
\text { pantanos de cualquier tipo que no se comuniquen directamente con el mar. Se } \\
\text { consideran dentro de esta categoría las parcelas que sin estar cubiertas de } \\
\text { agua de forma permanente, no pueden ser usadas, en un año ordinario, con } \\
\text { fines agrícolas, debido a su potencial de agua; } \\
\text { - Dentro de cada curso de agua o sección de curso de agua sometido a la } \\
\text { influencia de las mareas, la superficie cubierta por las mareas de coeficiente } \\
\text { 120; }\end{array}$ \\
\hline
\end{tabular}

Fuente: Bello et al., 2006.

La antigüedad y lo limitado de algunos de los textos citados pueden hacer pensar que todo el sistema jurídico marroquí es semejante; tal apreciación es sólo parcialmente cierta. Hay normativas mucho más recientes y elaboradas, muchas de las cuales afectan al litoral. Ya se ha citado la Ley 12-03 relativa a los Estudios de Impacto Ambiental, similar en calidad a las leyes actualmente vigentes en cualquier

\footnotetext{
${ }^{19}$ Para elaborar esta tabla se ha tenido en cuenta la modificación incluida por la ley 10-95 sobre el DP Hidráulico que abrogó los apartados d, e, f g y h del Dahir del 1 de Julio de 1914.
} 
país europeo. Pero hay otros ejemplos: La Ley sobre la Pesca Marítima del 23 de noviembre de 1973, que ha sido revisada y modificada en varias ocasiones (1990, 1992, 1995); estándose actualmente a la espera de que se apruebe el Proyecto de Ley del Código sobre Pesca marítima y la Protección de los Ecosistemas Marinos cuyo sugerente título habla por sí solo. También de carácter sectorial, está el Decreto n ${ }^{0}$ 95-717 de 22 de noviembre de 1996, sobre la Preparación y la Lucha contra la Contaminación Marina Accidental ${ }^{20}$.

Más interesante es Ley 11-03 sobre la Protección y la Puesta en Valor del Medio Ambiente. Su sección quinta del Capítulo III, que trata sobre la protección de los espacios y recursos marinos incluido el litoral, deja clara la necesidad de adoptar disposiciones legislativas y reglamentarias para prevenir y eliminar las actividades "susceptibles de alterar la calidad de las aguas y los recursos marinos; perjudicar la salud humana; dañar a la fauna, la flora 0 a los intereses relacionados con los mismos; y la calidad ambiental del medio marino en general" (art.33). Todo ello fijando las condiciones de exploración, explotación y puesta en valor de los recursos; adoptando las medidas necesarias para prevenir y luchar contra la contaminación marina; y estableciendo los criterios para clasificar las áreas especialmente protegidas. Desde un punto de vista más específico, en el art. 35 se establece que "deben tomarse las disposiciones legislativas y reglamentarias necesarias para garantizar la gestión integrada y sostenible del ecosistema litoral y la prevención ante cualquier degradación de los recursos"; y hasta se citan (art. 36), como mecanismos de aplicación, esquemas y planes de ordenación y explotación del litoral.

Es indudable que estamos ante una normativa de calidad, que pretende establecer las directrices generales de la política nacional integrada de medio ambiente. Una aproximación semejante sólo se ha logrado en los países europeos recientemente y tras una trabajosa evolución desde la protección de especies y espacios naturales; pasando por las políticas ambientales sectoriales, orientadas hacia problemas específicos, etc.

Es indudable, también, que esta normativa es fundamental para la preservación del litoral y su gestión integrada. Sin embargo, obviamente, su objetivo

\footnotetext{
${ }^{20}$ Aprobado el 22 de noviembre de 1996, publicado en el BO nº 4440 el 19 de diciembre de 1996.
} 
específico no es dicho espacio. En consecuencia no está pensada para resolver en solitario aspectos como: la indefinición de sus límites; la complejidad que le confiere su carácter fronterizo ${ }^{21}$; su peculiar dinamismo y las intensas tensiones a que está sometido por los procesos propios de la litoralización, incluido el pujante sector turístico.

En definitiva, la abundancia y juventud de las normativas ambientales, su calidad, consistencia y carácter innovador ${ }^{22}$, reflejan el interés de las autoridades marroquíes por el sector ambiental; y describen un proceso que parece haber sido más lento y menos penoso que en la otra orilla, cuyo interés por lo ambiental ha ido creciendo proporcionalmente al nivel de desarrollo...

Pero, entonces, ¿qué pasa con el litoral? A pesar de que las normas que acabamos de citar no están exentas de defectos o limitaciones, la consistencia de cualquier de ellas deja en evidencia las carencias respecto al litoral. A día de hoy la costa marroquí está en peligro y una de las causas fundamentales es la ausencia de un marco legislativo fuerte e integrador, que tenga en cuenta sus particularidades como ecosistema y ayude a sus gestores a proteger y mantener sus recursos. La indefinición del DPMT es fundamental al respecto.

\subsection{La política.}

Pero, ¿por qué no el litoral? En realidad hay indicios en todo lo anterior que demuestran que el litoral es un ámbito de interés para las autoridades marroquíes, tal vez incluso sea ese interés lo que está provocando el retraso en la aprobación de normativa ad hoc.

La primera versión del Proyecto de Ley relativo a la protección del litoral marroquí se presentó en septiembre de 1996; pero, en 1997, Marruecos obtuvo

\footnotetext{
${ }^{21}$ Entre la hidrosfera (salada y dulce), la litosfera y la atmósfera.

${ }^{22}$ El carácter preventivo de muchas disposiciones, la inclusión de medidas para que la información sea accesible al público, la inclusión de períodos de consulta pública (p.e. en la Ley de EIA), la intención de integrar, con objetivos ambientales, problemas que tradicionalmente se abordan por separado... son indicadores de modernidad.
} 
un Proyecto Life Países Terceros en el marco del cual su gobierno adquirió el compromiso de elaborar otro ante-proyecto de Ley relativo a la Protección del Litoral, que se presentó el 18 de junio de 1998.

En la tabla 5 aparecen los aspectos del citado documento más relacionados con la definición del ámbito costero: Como puede comprobarse, no hay nada dirigido específicamente al DPMT; en todo caso, se habla de ciertas "zonas anexas a la línea de costa", pero siempre tomando como referencia el límite superior de la pleamar. En cualquier caso, esta propuesta nunca llegó a aprobarse y desapareció por completo, de hecho durante mucho tiempo nos resultó imposible localizar un ejemplar original, y toda nuestra información se originó en la publicación de Sbä (2001).

Tabla 5. Principios generales del Capitulo II del Proyecto de Ley del Litoral de 1998

\begin{tabular}{|c|c|c|}
\hline Tema & Contenido Específico & Artículo \\
\hline \multirow[b]{2}{*}{$\begin{array}{l}\text { Zonas anexas a } \\
\text { la línea de costa }\end{array}$} & $\begin{array}{l}\text { - Se prohíbe toda construcción o instalación en una banda de } 100 \mathrm{~m} \text {. a partir } \\
\text { del límite superior a donde llegan las aguas más altas a lo largo del año. } \\
\text { Este espacio puede ampliarse cuando la sensibilidad del medio o la erosión } \\
\text { costera lo exijan. } \\
\text { Existe una excepción que es cuando la zona se encuentre ya urbanizada } \\
\text { o los servicios públicos ligados a actividades económicas necesiten la } \\
\text { proximidad inmediata del agua para su desarrollo. }\end{array}$ & 5 \\
\hline & $\begin{array}{l}\text { - Se prohíbe la creación de nuevas infraestructuras viarias próximas } \\
\text { a playas, dunas, lagunas y acantilados a menos de } 200 \mathrm{~m} \text {. de la } \\
\text { línea de costa. } \\
\text { Esta disposición no se aplica si la configuración del terreno no lo } \\
\text { permite. } \\
\text { También se permite la creación de carreteras en los espacios ya } \\
\text { urbanizados y en los casos en que los servicios públicos o las } \\
\text { actividades económicas que se desarrollan en la zona necesiten la } \\
\text { proximidad inmediata del mar. }\end{array}$ & 12 \\
\hline
\end{tabular}

Fuente: Bello et al., 2006.

En un informe interno realizado por el Departamento de Medio Ambiente marroquí en $2005^{23}$ sobre la situación actual del litoral se alude a la necesidad de elaborar un nuevo Proyecto de Ley; e incluso se citan los principales aspectos que debería tocar. Entre ellos destaca la necesidad de establecer una definición del

\footnotetext{
${ }^{23}$ La Cellule du Littoral. Eléments pour une stratégie de protection et de gestion intégrée du littoral (2005).
} 
litoral; teniendo en cuenta, tanto el propio concepto administrativo de DPMT, como su expresión ambiental, "incluyendo todas las zonas que forman parte del ecosistema marino". Ello supone un reconocimiento de la importancia de la delimitación del ámbito de gestión para poder actuar con eficiencia... aunque no estemos seguros de que se quiere decir, exactamente, con "ecosistema marino".

De forma más general, en dicho documento se indica también la necesidad de "establecer las disposiciones reglamentarias y operativas relacionadas con los mecanismos e instrumentos creados para la gestión integrada de las zonas costeras"; así como, de determinar las estructuras que deben elaborar y coordinar dicha política. En junio del 2006 se aprobó finalmente el último proyecto de Ley, y hasta el momento no hay ninguna otra novedad.

La existencia de tantos proyectos de Ley para el litoral en apenas diez años nos indica el interés de Marruecos por contar con una verdadera política al respecto, por contar con instrumentos normativos específicos y actuales... también podemos afirmar que dicho interés, sobre todo en su expresión más reciente, tiene una orientación ambiental e integradora. Cómo ya dijimos en el apartado legal, hay que admitir que el gobierno marroquí está trabajando dentro de las líneas más actuales en lo que respecta a la gestión costera, en particular, y a la ambiental, en general. Otra cosa es que pueda permitirse realmente desarrollar dicha estrategia. La repetición de los procesos y el hecho de que ninguna de las iniciativas haya terminado en la promulgación de una Ley, a parte de reflejar la proverbial lentitud de la administración Marroquí nos lleva a pensar en un proceso especialmente dificultoso.

El caso es que, a día de hoy, en plena expansión turística, Marruecos aún no cuenta con una legislación específica para la costa. Este problema debería solucionarse con urgencia; de no ser así, su litoral corre un serio peligro, ya que las administraciones marroquíes competentes en la gestión de la costa y sus recursos, están viéndose obligadas a resolver problemas actuales con leyes obsoletas e inadecuadas. Es urgente aprobar una ley del litoral, aunque no sea perfecta, pues no hay peor situación que la ausencia de norma (Bello, et al., 2006). 


\section{CONCLUSIONES.}

La principal conclusión es, seguramente, una terrible desazón. Es cómo si, mientras presenciamos las fases finales de una terrible enfermedad... viésemos con horror sus primeros síntomas, aún apuntando pero evidentes, en aquel que tenemos enfrente. $Y$ además, si tenemos la terrible sospecha de que somos nosotros quienes se la hemos transmitido, tal responsabilidad nos quita fuerza moral para prevenirle.

Las condiciones físicas y naturales de ambas orillas son muy semejantes $y$, constituyen un recurso de interés turístico indudable. Las condiciones sociales y económicas de ambas orillas en el momento de inicio del proceso turístico también son parecidas: En definitiva, se trata de sociedades que no pueden permitirse rechazar una oferta de desarrollo, no están en condiciones de hacerlo; Sazonada la realidad marroquí con una información contundente e inexacta que relaciona, de forma rápida y directa, crecimiento turístico con desarrollo; Ignorando, además, peculiaridades nacionales y culturales, coyunturas inadecuadas, así como la fragilidad endémica del sector. En definitiva, tienen lo que en la otra orilla no existió en su momento, al menos de forma tan evidente, un modelo a seguir y van hacia él con más afán y decisión si cabe.

Afortunadamente, no sólo se está siguiendo un modelo económico, sino también jurídico, no sólo se imita lo que se hace... sino lo que debería hacerse. Es evidente que el sistema de Marruecos ha evolucionado en este sentido de forma muy dinámica, situándose dentro de las líneas más actuales al respecto: hacia la sostenibilidad desde perspectivas integradoras. Sin embargo, dicho enfoque dista tanto de la situación socio-económica marroquí que es difícil pensar que vaya a tener éxito, las prioridades son otras ahora. Es dudoso que este inusual avance en los instrumentos administrativos pueda aplicarse: ni las normas ni las políticas resuelven problemas si su distancia respecto a la realidad es tan grande que no pueden verla. Cuando las reglas se adelantan tan considerablemente a las necesidades sociales hay que analizar profundamente las causas, quizás detrás de todo ello está la vieja idea de que el papel lo aguanta todo.

Quizás la ausencia de regulación específica del litoral si responde a la situación real de Marruecos: allí donde hay ya procesos en marcha, donde hay intereses reales en juego, donde las presiones son constantes, no es fácil legislar... sobre todo cuando 
existen normativas antiguas e ineficaces que, en la práctica, dejan abiertas todas las posibilidades.

Quizás quede un resquicio para la esperanza pues, por diversas razones, la ocupación de la orilla marroquí se ha retrasado considerablemente respecto a la española... ¿Podría aprenderse de la experiencia? ¿Podría lograrse un cambio de modelo? ¿Podrían, al menos, introducirse algunos cambios? Las acuciantes necesidades de la orilla marroquí y el aparente éxito que se desprende de la orilla española no invitan al optimismo. Pero, cómo ya se dijo, en ello andamos.

\section{BIBLIOGRAFÍA.}

Anfuso, G., Benavente, J., Nachite, D., El Moutchou, B., Bello, E., Macías, A. 2004. Caracterización morfodinámica de las playas del tramo costero marroquí entre Ceuta y Cabo Negro. Geogaceta, 35: 47-50.

Anfuso, G.; Benavente, J. y Nachite, D. 2006. Características físico-naturales más destacadas de la zona de estudio: la geomorfología. En: Estudios previos para una propuesta de gestión integrada en las costas mediterráneas de Marruecos: el tramo Ceuta-Cabo Negro, Cádiz, UCA, Universidad Abdelmalek Essâadi y Junta de Andalucía, pp. 9-27.

Ávila Orive, J.L. 1998. El suelo como elemento ambiental: Perspectiva territorial y urbanística. Bilbao, Universidad de Deusto, 325 pp.

Bello, E.(et al.) 2006. Estudios previos para una propuesta de gestión integrada en las costas mediterráneas de Marruecos: el tramo Ceuta-Cabo Negro, Cádiz, UCA, Universidad Abdelmalek Essâadí y Junta de Andalucía, 103 pp.

Barragán Muñoz, J.M. 2003. Medio ambiente y desarrollo en áreas litorales. Introducción a la planificación y gestión integradas. Cádiz, Universidad de Cádiz, 301 pp.

Barragán Muñoz, J. M. 2004. Las áreas litorales de España. Del análisis geográfico a la gestión integrada, Barcelona, Ariel 214 pp. 
Comisión Europea 1999. Estrategia Territorial Europea (ETE). Hacia un desarrollo equilibrado y sostenible del territorio de la UE). Luxemburgo, Oficina de Publicaciones Oficiales de la CE.

Fischer, D. 1999. Técnicas para la formulación de políticas en zonas costeras, México, Universidad Autónoma de Baja California, 244 pp.

Fernández Tabales, A. 2003. Actividades y espacios turísticos. Geografía de Andalucía. Barcelona, Ariel Geografía, pp. 723-784.

Gabiña, J. 1998. Prospectiva y Ordenación del Territorio. Hacia un proyecto de futuro. Barcelona, Marcombo.

García Fernández, J. 1994. Los problemas del medio ambiente y la Ordenación del Territorio, Medio Ambiente y Ordenación del Territorio, Salamanca, Universidad de Valladolid, pp. 7-31.

Hildebrand Scheid, A.H. 1996. Política de Ordenación del Territorio en Europa. Sevilla, Universidad de Sevilla y Consejería de Obras Públicas y Transportes.

Jordá Borrell, R. M. 1987. Población, economía y territorio en Andalucía. Geografía de Andalucía. Sevilla, Ediciones Tartesos, pp. 137-206

Macías Bedoya, A. M. y Barragán Muñoz, J.M. 2005. El litoral andaluz y su protección. Parque Natural del Estrecho. Sevilla, Consejería de Medio Ambiente

Nachite, D., El Moutchou, B., Anfuso, G., Benavente, J., Bello, E., Macías, A. 2004. Morfología y evolución reciente del litoral entre Fnideq y M'diq (Tetuán, NE de Marruecos). Geogaceta, 35: 43-46.

Observatoire National de l'Environnement du Maroc (ONEM). 2001. Rapport sur l'Etat de l'Environnement du Maroc. Inédito.

Sbaï, L. 2001. Le droit de l'environnement marin et côtiere marocain. Dichotomie entre l'etat du milieu et una législation obsolète. Rabat, Presses des belles Couleurs, $146 \mathrm{pp}$. 